\title{
PENGARUH JARAK TANAM TERHADAP PERTUMBUHAN DAN HASIL TANAMAN SAWI HIJAU (Brassica Juncea L)
}

\author{
Emilia S.A. Wangge', Maria Felmi Fowo \\ Emilia_wangge@yahoo.co.id
}

\begin{abstract}
ABSTRCT
This study aims at determining the optimum planting distance on the growth and yield of Bok Choy Sum plant, determining optimum planting distance of mustard greens plant that can optimize the growth and yield of Bok Choy Cum plant.

This study employed group random design with single factor pattern including 5 treatments, namelyPD0: Planting Distance $10 \mathrm{~cm}$ x $20 \mathrm{~cm}$, PD1: Planting Distance $15 \mathrm{~cm}$ x $10 \mathrm{~cm}$, PD2: Planting Distance $15 \mathrm{~cm}$ x $15 \mathrm{~cm}$, PD3: Planting Distance $15 \mathrm{~cm}$ x $20 \mathrm{~cm}$, PD4: Planting Distance $20 \mathrm{~cm}$ x $20 \mathrm{~cm}$. All treatments were repeated four times so that there were 20 specimen garden-beds.

The treatment of planting distance on Bok Choy Sumhas an impact on plant height, the width of leaves, but it did not have the impact on the number of leaves. The treatment of planting distance on result variablehas real impact on variable of Bok Choy Sum ${ }^{-1}$ weight andBok Choy Sum weight ha ${ }^{-1}$. Planting distance $20 \mathrm{~cm}$ x $20 \mathrm{~cm}$ can optimize the growth and yield of Bok Choy Sum.
\end{abstract}

Keywords: Planting distance, Bok Choy Sum plants

\section{PENDAHULUAN}

Sawi (Brassica chinensis L.) merupakan

salah satu jenis sayur yang digemari oleh

masyarakat Indonesia. Konsumennya mulai

dari golongan masyarakat kelas bawah

hingga golongan masyarakat kelas atas. Di

Indonesia sendiri banyak sekali jenis

masakan atau panganan yang menggunakan

daun sawi, baik sebagai bahan pokok

maupun sebagai bahan pelengkapnya.

Ditinjau dari aspek ekonomis dan bisnis, sawi layak diusahakan untuk memenuhi permintaan konsumen yang cukup tinggi dan peluang pasar internasional yang cukup besar.

Berdasarkan data dari Biro Pusat Statistik (BPS) tentang Survei Pertanian Produksi Tanaman Sayuran di Nusa Tenggara Timur tahun 2011, luas panen tanaman sawi adalah 1.350 ha, dengan ratarata produksi 2.86 ton/ha, dan jumlah produksi 3.858 ton/ha, sementara itu 


\section{Emilia: PENGARUH JARAK TANAM TERHADAP PERTUMBUHAN DAN HASIL TANAMAN SAWI HIJAU (Brassica Juncea L)}

produksi sawi Kabupaten Ende sebesar 315 tan/ha, produktivitas $15.67 \mathrm{kw} / \mathrm{ha}$, luas tanam 22.20 ha dan luas panen 20.10 ha (BPS Kabupaten Ende, 2011).

Pengembangan budidaya sawi mempunyai prospek baik untuk mendukung upaya peningkatan pendapatan petani, peningkatan gizi masyarakat, perluasan kesempatan kerja, pengembangan agribisnis, peningkatan pendapatan negara melalui pengurangan impor dan memacu laju pertumbuhan ekspor. Kelayakan pengembangan budidaya sawi antara lain ditunjukkan oleh adanya keunggulan komparatif kondisi wilayah NTT yang sangat cocok untuk komoditas tersebut. Disamping itu,umur panen sawi relative pendek yakni antara 40-70 hari setelah pindah tanam (hpst), dan hasilnya memberikan keuntungan yang memadai.

Salah satu jenis tanaman sawi yang cukup banyak dikembangkan oleh petani di Ende adalah sawi hijau (Brassica Juncea
L.). Upaya peningkatan produksi tanaman sawi hijau dapat dilakukan, antara lain dengan pengaturan jarak tanam yang tepat. Menurut Badan Pengendali Bimas (1997) pengaturan jarak tanam yang tepat dapat memperkecil persaingan antara tanaman dalam hal pengembalian unsur hara,air,sinar matahari dan ruang tumbuh tanaman. Selain itu jarak tanam yang tepat juga dapat menekan pertumbuhan gulma, sehingga persaingan tanaman dengan gulma dapat dihindari.

Menurut Haryanto (2007), sawi dapat ditanam pada bedengan dengan ukuran lebar $120 \mathrm{~cm}$ dan panjang sesuai dengan ukuran petak tanah.Tinggi bedeng $20-30 \mathrm{~cm}$ dengan jarak antar bedeng $30 \mathrm{~cm}$, seminggu sebelum penanaman dilakukan pemupukan terlebih dahulu yaitu pupuk kandang 10 ton/ha,TSP 100kg/ha, Kel 75 kg/ha. Sedang jarak tanam dalam bedengan $20 \mathrm{~cm}$ x $20 \mathrm{~cm}$. Jarak tanam sangat erat kaitannya dengan jumlah anakan yang akan dihasilkan. Ini 


\section{Emilia: PENGARUH JARAK TANAM TERHADAP PERTUMBUHAN DAN HASIL TANAMAN SAWI HIJAU (Brassica Juncea L)}

berarti jarak tanam erat kaitannya dengan jumlah hasil yang akan diperoleh dalam sebidang tanah. Karena itu pengaturan jarak tanam perlu diperhatikan untuk memenuhi sasaran agronomi yaitu produksi yang maksimal.

Selama ini ditingkat petani pengaturan jarak tanam sawi biasanya tanpa perhitungan secara khusus tetapi hanya berdasarkan kebiasaan tanpa mengetahui jarak tanam yang tepat untuk penanaman tanaman sawi. Berdasarkan hal di atas maka perlu dilakukan penelitian "Pengaruh Jarak Tanam Terhadap Pertumbuhan dan Hasil Tanaman Sawi Hijau (Brassica juncea L.)”.

METODELOGI PENELITIAN

Tempat dan Waktu

Percobaan ini dilaksanakan di Kelurahan Rewarangga Selatan, Kecamatan Ende Timur, Kabupaten Ende. Pelaksanaan penelitian dilakukan pada bulan Juni Agustus 2013.

\section{Bahan dan Alat}

Bahan-bahan yang digunakan dalam percobaan ini adalah benih sawi varietas sawi hijau. Alat-alat yang digunakan adalah pacul, sabit, ajir, ember plastik, sekop, timbang, oven, meteran, penggaris, tali raffia, kantong plastik, alat tulis, dan kamera.

\section{Rancangan Percobaan}

Rancangan yang digunakan dalam percobaan ini adalah Rancangan Acak Kelompok (RAK) dengan pola faktor tunggal yang terdiri dari lima perlakuan yaitu : JT1: Jarak Tanam $10 \mathrm{~cm} \mathrm{x} 20 \mathrm{~cm}$, JT2: Jarak Tanam $15 \mathrm{~cm} \mathrm{x} 10 \mathrm{~cm}$, JT3: Jarak Tanam $15 \mathrm{~cm}$ x $15 \mathrm{~cm}$ JT4 : Jarak Tanam $15 \mathrm{~cm}$ x $20 \mathrm{~cm}$ dan JT5: Jarak Tanam 20 x $30 \mathrm{~cm}$.

Semua perlakuan diulang sebanyak empat kali sehingga terdapat 20 petak percobaan.

Variabel Pengamatan Variabel Pertumbuhan

1. Tinggi tanaman $(\mathrm{cm})$. 


\section{Emilia: PENGARUH JARAK TANAM TERHADAP PERTUMBUHAN DAN HASIL TANAMAN SAWI HIJAU (Brassica Juncea L)}

Tinggi tanaman diukur mulai dari permukaan tanah sampai daun tertinggi yaitu yang tegak alami. Pengukuran dilakukan pada tanaman sampel pada umur dua minggu setelah tanaman dengan interval lima hari yakni : 7 hst, 14 hst, 21 hst dan 28 hst.

2. Jumlah daun (helai).

Daun yang dihitung yaitu daun yang telah terbuka penuh dan minimal $50 \%$ masih berwarna hijau. Pengamatan jumlah daun tanaman-1 dilakukan pada lima tanaman sampel umur 7 hst, 14 hst, 21 hst dan 28 hst.

3. Luas daun $\left(\mathrm{cm}^{2}\right)$.

Luas daun ditentukan dengan panjang $\mathrm{x}$ lebar daun maksimal $\mathrm{x}$ konstanta. Konstanta dicari dengan menghitung luas daun sebenarnya di atas kertas milimeter kemudian dibagi dengan panjang x lebar daun maksimal.

\section{Variabel Hasil}

1. Berat berangkasan segar tan-1 (g)
Berat berangkasan segar tan-1 diperoleh dengan menimbang seluruh berangkasan baik akar, batang, daun yang dipanen dalam tanaman sampel kemudian hasilnya dirata-ratakan.

2. Berat sawi ha ${ }^{-1}$ (ton).

Berat segar/ha dihitung dengan cara mengkonversikan berat segar per tanaman dikalikan dengan populasi tanaman per hektar.

\section{Analisis Data}

Data hasil pengamatan dengan menggunakan analisis sidik ragam sesuai dengan rancangan yang digunakan. Apabila perlakuan menunjukan pengaruh yang nyata atau sangat nyata terhadap variabel yang diamati, maka pengujian dilanjutkan dengan uji nilai beda rata-rata menggunakan uji BNT 5 \% (Gomez dan Gomez, 2007).

\section{HASIL DAN PEMBAHASAN}




\section{Emilia: PENGARUH JARAK TANAM TERHADAP PERTUMBUHAN DAN HASIL TANAMAN SAWI HIJAU (Brassica Juncea L)}

Hasil analisis statistik menunjukan bahwa perlakuan jarak tanam berpengaruh sangat nyata terhadap tinggi tanaman 14 hst, 21 hst, 28 hst, Luas daun 7 hst, 14 hst, 21 hst, 28 hst, berat segar sawi tanaman ${ }^{-1}$, berat sawi tanaman hektar dan berpengaruh tidak nyata terhadap tinggi tanaman 7 hst, jumlah daun 7 hst, 14hst, 21 hst, 28 hst.

\section{Variabel Pertumbuhan}

Tinggi Tanaman, Jumlah Daun dan Luas daun

Hasil analisis sidik ragam menunjukan jarak tanam yang berbeda memberikan pengaruh yang sangat nyata terhadap tinggi tanaman dan luas daun kecuali pengaruh tidak nyata terhadap tinggi tanaman 7 hst dan jumlah daun 7, 14,21, dan 28 hst.

Tinggi tanaman pada umur 7 hst tidak berpengaruh nyata terhadap semua perlakuan jarak tanam. Umur tanaman 14,21 dan 28 hst menunjukkan tinggi tanaman tertinggi pada perlakuan jarak tanam $20 \mathrm{~cm} \quad x \quad 30 \mathrm{~cm}$. Jumlah daun menunjukan pengaruh tidak nyata terhadap semua perlakuan, pada perlakuan jarak tanam $20 \mathrm{~cm} \mathrm{x} 30 \mathrm{~cm}$ jumlah daun yang paling banyak jika dibandingkan dengan perlakuan jarak tanam lainnya. Luas daun sawi menunjukan pengaruh sangat nyata terhadap seluruh pelakuan, luas daun yang tertinggi pada umur tanaman sawi 28 hari pada jarak tanam jarak tanam $20 \mathrm{~cm}$ x $30 \mathrm{~cm}$ jika dibandingkan dengan lainnya. Peningkatan tinggi tanaman, jumlah daun dan luas daun menunjukan bahwa hipotesis pertama diterima dan hipotesis ke dua diterima.

Berdasarkan pada parameter tinggi tanaman diketahui bahwa pada tanaman sawi ternyata tinggi tanaman lebih tinggi pada jarak tanam $20 \mathrm{~cm}$ x $30 \mathrm{~cm}$, mengacu pada pendapat Kertasapoetra (1988) dalam jarak tanam yang rapat terjadi kompetisi dalam penggunaan cahaya. 
Emilia: PENGARUH JARAK TANAM TERHADAP PERTUMBUHAN DAN HASIL TANAMAN SAWI HIJAU (Brassica Juncea L)

Tabel 4.2 Pengaruh Jarak Tanam Terhadap Tinggi Tanaman, Jumlah Daun dann luas daun tanaman sawi

\begin{tabular}{|c|c|c|c|c|}
\hline $\begin{array}{c}\text { Umur } \\
\text { Tanaman }\end{array}$ & Perlakuan & $\begin{array}{c}\text { Tinggi } \\
\text { tanaman }(\mathbf{c m})\end{array}$ & $\begin{array}{c}\text { Jumlah Daun } \\
\text { (Helai) }\end{array}$ & $\begin{array}{c}\text { Luas daun } \\
\left(\mathrm{cm}^{2}\right)\end{array}$ \\
\hline \multirow{5}{*}{7 HST } & JT1 & $8.58 \mathrm{a}$ & $3 a$ & $19.36 c$ \\
\hline & JT2 & $8.78 \mathrm{a}$ & $3 a$ & $27.17 b$ \\
\hline & JT3 & $8.52 \mathrm{a}$ & $3 a$ & $27.94 b$ \\
\hline & JT4 & $8.6 \mathrm{a}$ & $3 a$ & $31.25 \mathrm{a}$ \\
\hline & JT5 & $9.72 \mathrm{a}$ & $4 a$ & $32.44 \mathrm{a}$ \\
\hline \multirow[t]{2}{*}{ BNT } & & $\mathbf{T N}$ & TN & 1,655 \\
\hline & JT1 & $12.52 \mathrm{~b}$ & $4 a$ & $20.44 c$ \\
\hline & JT2 & $12.64 b$ & $4 a$ & $28.15 b$ \\
\hline \multirow[t]{3}{*}{14 HST } & JT3 & $12.58 b$ & $4 a$ & $29.09 b$ \\
\hline & JT4 & $12.68 b$ & $4 a$ & $32.40 \mathrm{a}$ \\
\hline & JT5 & $14.86 \mathrm{a}$ & $5 \mathrm{a}$ & $33.44 \mathrm{a}$ \\
\hline \multirow[t]{3}{*}{ BNT } & & 0,14 & TN & 1,892 \\
\hline & JT1 & $16.38 \mathrm{c}$ & $4 a$ & $21.76 \mathrm{e}$ \\
\hline & JT2 & $16.76 \mathrm{~b}$ & $4 a$ & $32.39 \mathrm{c}$ \\
\hline \multirow[t]{3}{*}{$21 \mathrm{HST}$} & JT3 & $16.64 b$ & $4 a$ & $30.49 d$ \\
\hline & JT4 & $17.78 b$ & $4 a$ & $34.40 \mathrm{~b}$ \\
\hline & JT5 & $19.78 \mathrm{a}$ & $7 \mathrm{a}$ & $37.46 \mathrm{a}$ \\
\hline \multirow[t]{3}{*}{ BNT } & & 0,24 & TN & 1,3 \\
\hline & JT1 & $20.52 c$ & $6 a$ & $24.20 \mathrm{e}$ \\
\hline & JT2 & $20.68 \mathrm{c}$ & $6 a$ & $32.43 d$ \\
\hline \multirow[t]{3}{*}{28 HST } & JT3 & $20.52 c$ & $6 a$ & $34.64 \mathrm{c}$ \\
\hline & JT4 & $22.7 b$ & $6 a$ & $37.52 b$ \\
\hline & JT5 & $25.84 \mathrm{a}$ & $8 \mathrm{a}$ & $39.48 \mathrm{a}$ \\
\hline BNT & & 0,28 & TN & 0,214 \\
\hline
\end{tabular}

Keteranagan : Angka-angka yang diikuti oleh huruf yang sama pada kolomyang sama menunjukan pengaruh yang tidak berbeda nyata pada taraf uji BNT 5\%

Dalam penelitian ini dimungkinkan dengan adanya kerapatan populasi yang tinggi maka terjadi kompetisi dalam mendapatkan unsur hara, dengan intensitas cahaya matahari diterima rendah maka tanaman melakukan pemanjangan sel, sehingga tanaman lebih tinggi dari pada 62 tanaman yang mendapatkan penyinaran matahari yang cukup.

Berdasarkan parameter jumlah daun, ternyata tidak ada perbedaan sama sekali pada semua perlakuan, menurut Kramer (1969) bahwa pertumbuhan bagian tanaman atas permukaan tanaman tergantung oleh 


\section{Emilia: PENGARUH JARAK TANAM TERHADAP PERTUMBUHAN DAN HASIL TANAMAN SAWI HIJAU (Brassica Juncea L)}

sistem perakarannya. Lebih lanjut

diterangkan bahwa pembentukan daun

ditentukan oleh faktor lingkungan yang

antara lain; iklim, tanah, dan faktor unsur

hara dalam tanah. Saat masuk pada fase

pertumbuhan daun, tanaman lebih banyak

menyerap unsur hara dalam tanah dan

banyak membutuhkan cahaya matahari.

(Leopold dan Kriedman, 1975 dalam

Nurmawati, 2001). Dengan masih

tercukupinya unsur hara dalam media tanam,

juga penanaman yang serempak

memungkinkan pada fase pembentukan

daun tidak ada ganguan sehingga tidak ada

perbedaan dalam jumlah daun. Perbedaan

hanya terjadi pada luas daun.

Garder, (1991) menyatakan bahwa jika

tanaman terlalu rapat maka berpengaruh

pada pertumbuhan tanaman akibat dari

menurunnya laju fotosintesis dan

perkembangan daun. Kerapatan tanam

sangat mempengaruhi perkembangan vegetatif tanaman dan juga mempengaruhi tingat produksi panen suatu tanaman.

Pengaturan populasi tanaman melalui pengaturan jarak tanam pada suatu tanaman akan mempengaruhi koefisien tanaman dalam memanfaatkan matahari dan pesaingan tanaman dalam peman-faatan hara dan air yang pada akhirnya akan mempengaruhi pertumbuhan dan produksi tanaman. Dengan pengaturan jarak tanam yang baik, maka pemanfaatan ruang yang ada bagi pertumbuhan tanaman dan kapasitas penyangga terhadap peristiwa yang merugikan dapat diefesienkan. Berdasarkan hal tersebut di atas, maka perlu melakukan kajian untuk mengetahui pengaruh sistem jarak tanam terhadap pertumbuhan dan produksi tanaman (Musa dkk, 2007).

\section{Variabel Hasil}

Hasil analisis sidik ragam menunjukan bahwa perlakuan jarak tanam yang berbeda memberikan pengaruh sangat 


\section{Emilia: PENGARUH JARAK TANAM TERHADAP PERTUMBUHAN DAN HASIL TANAMAN SAWI HIJAU (Brassica Juncea L)}

nyata terhadap berat segar sawi $\tan ^{-1}$ dan $\quad$ berat ha $^{-1}$.

Tabel 4.3. Pengaruh Jarak Tanam terhadap Variabel Produksi

\begin{tabular}{ccc} 
Perlakuan & Berat segar tan $^{-1}$ & Berat/ha $^{-1}$ \\
\hline JT 1 & $53.0 \mathrm{e}$ & $1.87 \mathrm{e}$ \\
JT 2 & $67.0 \mathrm{~d}$ & $2.670 \mathrm{c}$ \\
JT 3 & $75.1 \mathrm{c}$ & $2.35 \mathrm{~d}$ \\
JT 4 & $80.1 \mathrm{~b}$ & $3.35 \mathrm{~b}$ \\
JT 5 & $93.4 \mathrm{a}$ & $6.22 \mathrm{a}$ \\
\hline BNT 5\% & $\mathbf{3 5 . 5 3}$ & $\mathbf{1 2 . 2 3}$ \\
\hline Keterangan & : Angka-angka yang diikuti oleh huruf yang sama pada kolomyang sama
\end{tabular}

Perlakuan jarak tanam terhadap menyerap unsur hara yang tersedia dalam produksi hasil menunjukan bahwa jarak tanah dan juga didukung oleh jarak tanam $20 \times 30 \mathrm{~cm}$ memberikan peningkatan berat yang optimal sehingga tidak terjadi brangkasan pertanaman dan berat persaingan dalam memperebutkan unsure brangkasan per hektar yang lebih tinggi jika hara.

dibandingkan dengan perlakuan jarak tanam Pertumbuhan tanaman sangat lainnya. Hal ini diduga pada jarak $20 \times 30$ dipengaruhi oleh jarak tanam, karena $\mathrm{cm}$ tidak terjadi persaingan perebutan unsur populasi yang terlalu padat akan hara sehingga pertumbuhannya lebih baik. menyebabkan terjadinva kompetisi untuk Hal ini menunjukkan bahwa hipotesis kedua memperebutkan zat hara dan sinar matahari terbukti karena dilihat dari jarak tanan yang (Haryanto et all, 1995). Perbedaan jarak berjauhan maka kesempatan tanaman sawi tanam mempengaruhi laju pertumbuhan untuk mendapatkan unsure hara lebih besar. tanaman. Semakin rapat jarak tanam maka Peningkatan berat tanaman sawi tidak semakin terjadi persaingan antar tanaman terlapas dari kemampuan tanaman dalam dan semakin lebar jarak tanam maka 


\section{Emilia: PENGARUH JARAK TANAM TERHADAP PERTUMBUHAN DAN HASIL TANAMAN SAWI HIJAU (Brassica Juncea L)}

semakin besar kesempatan tanaman untuk memenuhi unsur hara. Menurut Harjadi (1980), pertumbuhan tanaman sangat dipengaruhi oleh faktor internal yaitu jenis varietas dan faktor eksternal yaitu faktor lingkungan tumbuh.

Upaya peningkatan produksi tanaman perluasan tertentu dapat dilakukan dengan meningkatkan populasi tanaman dengan jarak tanam turut mempengaruhi produktifitas tanaman. Kerapatan atau ukuran populasi tanaman sangat penting untuk memperoleh hasil yang optimal, tetapi bisa terjadi persaingan dalam hara, air dan ruang tumbuh serta mengurangi perkembangan tinggi dan kedalaman akar tanam-an (Musa dkk, 2007).

\section{KESIMPULAN}

1. Perlakuan jarak tanam pada tanaman sawi menunjukkan bahwa perlakuan jarak tanam berpengaruh nyata terhadap tinggi tanaman, luas daun dan tidak berpengaruh nyata terhadap jumlah daun. Perlakuan jarak tanam pada variabel hasil menunjukkan pengaruh sangat nyata terhadap variabel berat segar sawi ${ }^{-1}$ dan berat segar sawi ha ${ }^{-1}$.

2. Jarak tanam $20 \mathrm{~cm} \times 30 \mathrm{~cm}$ yang memberikan pertumbuhan dan hasil yang optimal pada tanaman sawi.

\section{UCAPAN TERIMA KASIH}

Pada kesempatan ini penulis ingin mengucapkan terima kasih kepada semua pihak yang telah membantu dengan caranya masing-masing dalam melengkapi tulisan ini.

\section{DAFTAR PUSTAKA}

Anneahira. Manfaat Sawi

Hijau.http://www.anneahira,

com/manfaat-sayur- sawi.htm.Diakses tanggal 10 Maret 2011.

Balai Pengkajian Tekhnologi Jakarta. 2009.Tekhnologi Produksi Sayuran Sawi http://jakarta.litbang.deptan.go.id.Diakses tanggal 28 Februari 2011.

Cahyono. 2003.Tanaman Holtikultura, Penebar, Swadaya ,Jakarta 


\section{Emilia: PENGARUH JARAK TANAM TERHADAP PERTUMBUHAN DAN HASIL TANAMAN SAWI HIJAU (Brassica Juncea L)}

Fahrudin. 2009. Budidaya Caisim Menggunakan Ekstrak the dan Pupuk Kascing, Skripsi, Universitas Sebelas Maret.

Haryanto. E. T. Suhartini, dan E. Rahayu, 2001, Sawi dan Selada, Penebar Swadaya. Jakarta.

Garder. 1991. Fisiologi Tanaman Budidaya. UI Press, Jakarta

Heru dan Novita. 2003.Budidaya Tanaman

Holtikultura.Bina Aksara.Jakarta

http://ntt.bps.go.id/index.php/pertanian/holti kultura/35 data/holtikultura/167- luaspanen-rata-rata-nusa-tenggara-timur2011.

Margianto. E. 2007.Budidaya Tanaman Sawi, http://zuldesains, wordpress.com/2008/01/11/budidayatanaman- sawi/.Diakses tanggal 1 Maret 2011

Musa Y. Nasaruddin, M.A. Kuruseng, 2007. Evaluasi produktivitas jagung melalui pengelolaan populasi ta-naman, pengolahan tanah, dan dosis pemupukan. Agrisistem 3 (1): $21-33$

Musa. 2007. Pengaruh Pengaturan EC ( Electro-conduktivity) dan jarak tanam terhadap Pertumbuhan dan Hasil Tanaman Caisim ( Brassica juncea L.) Novizan. 2007.Sawi dan Selada.Penebar Swadaya ,Jakarta.
Nurmawati, 2001. Studi Komposisi Nutrisi dan Media Tanam terhadap Pertumbuhan Hasil Tanamn Tomat. Skripso SI Fakultas Pertanian UNS, Surakarta.

Rukmana. R.2002. Bertanam Sayuran Petsai dan Sawi.Kanisius, Yogyakarta.

Supriati, Yani dan Herliana, Ersi.2010.Bertanam 15 Sayuran Organik Dalam Pot.Penebar Swadaya,Jakarta.

Susila, Anas, D.2006.Panduan Budidaya Tanaman Sayuran.Departemen Agronomi dan Holtikultura, Fakultas Pertanian, IPB www.plantamor.com 